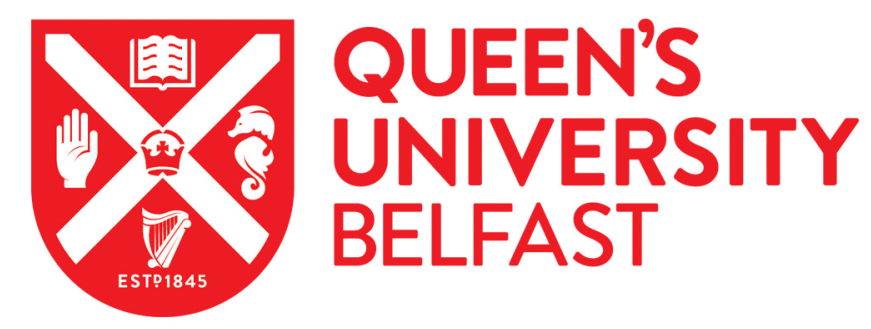

\title{
Long live the worms: Methods for maintaining and assessing the viability of intestinal stages of Parascaris spp. in vitro
}

Mousley, A. (2018). Long live the worms: Methods for maintaining and assessing the viability of intestinal stages of Parascaris spp. in vitro. Parasitology. https://doi.org/10.1017/S0031182018002019

\author{
Published in: \\ Parasitology
}

Document Version:

Peer reviewed version

Queen's University Belfast - Research Portal:

Link to publication record in Queen's University Belfast Research Portal

Publisher rights

Copyright 2018 Cambridge University Press. This work is made available online in accordance with the publisher's policies. Please refer to any applicable terms of use of the publisher.

\section{General rights}

Copyright for the publications made accessible via the Queen's University Belfast Research Portal is retained by the author(s) and / or other copyright owners and it is a condition of accessing these publications that users recognise and abide by the legal requirements associated with these rights.

Take down policy

The Research Portal is Queen's institutional repository that provides access to Queen's research output. Every effort has been made to ensure that content in the Research Portal does not infringe any person's rights, or applicable UK laws. If you discover content in the Research Portal that you believe breaches copyright or violates any law, please contact openaccess@qub.ac.uk. 
1 Long live the worms: Methods for maintaining and assessing the viability of intestinal stages of

2 Parascaris spp. in vitro

3 J.A. Scare ${ }^{a *}$, A.E. Steuer ${ }^{a}$, C.L. Shaffer ${ }^{a}$, P. Slusarewicz ${ }^{b}$, A. Mousley ${ }^{c}$, and M.K. Nielsen ${ }^{a}$

$4 \quad$ M.H. Gluck Equine Research Center

51400 Nicholasville Road

$6 \quad$ Lexington, KY 40514

7

8 Longevity and viability of Parascaris spp. in vitro

9

$10 *$ Corresponding author

11 Jessica Scare

12 E-mail: Jessica.scare@uky.edu

13 Address: M.H. Gluck Equine Research Center

141400 Nicholasville Road

15 Lexington, $K Y 40514$

16 Telephone: 859-257-4757

17 Fax: $+1-859-257-8542$

18

$19{ }^{a}$ M.H. Gluck Equine Research Center, Department of Veterinary Science, University of Kentucky, 20 Lexington, $K Y, U S A$

$21{ }^{b}$ MEP Equine Solutions, 3905 English Oak Circle, Lexington, KY 40514, USA

22

23 'School of Biological Sciences, Queen's University Belfast, Belfast, Ireland

24

25

26 
Abstract

29 In vitro maintenance of helminth parasites enables a variety of molecular, pharmaceutical, and

30 immunological analyses. Currently, the nutritional and environmental in vitro requirements of the

31 equine ascarid parasite, Parascaris spp., have not been determined. Additionally, an objective method

32 for assessing viability of Parascaris spp. intestinal stages does not exist. The purpose of this study was to

33 ascertain the in vitro requirements of intestinal stages of Parascaris spp., and to develop a viability

34 assessment method. A total 1045 worms were maintained in a total of 212 cultures. Worms obtained

35 from naturally infected foals at necropsy were immediately placed in culture flasks containing $200 \mathrm{~mL}$ of

36 culture media. A variety of media types, nutrient supplementation, and environmental conditions were

37 examined. A motility-based scoring system was used to assess worm viability. Worms maintained in

38 Roswell Park Memorial Institute- 1640 had significantly better viability than any other media $(p<0.0001)$

39 and all media types supplemented with any of the nutrients examined $(p<0.0001)$. The use of a platform

40 rocker also significantly improved viability $(p=0.0305)$. This is the first study to examine the

41 requirements for maintaining Parascaris spp. intestinal stages in vitro and to evaluate their viability

42 based on movement using an objective scoring system.

43 Keywords: Parascaris, in vitro, helminth, maintenance, ascarid, viability 
- Identified in vitro maintenance requirements for Parascaris spp. intestinal stages

- Novel approach to assess viability of intestinal stages of Parascaris spp.

- Parascaris spp. had significantly better viability when maintained in RPMI media

- Glucose and $\mathrm{CO}_{2}$ did not significantly affect worm viability

- Female worms had significantly better viability than males and $\mathrm{L}_{4} \mathrm{~S}$ 


\section{Introduction}

Parascaris spp. is a clinically important helminth parasite infecting foals (Clayton and Duncan,

52 1978; Cribb et al. 2006; Tatz et al. 2012) with anthelmintic resistance reported world-wide (Peregrine et

53 al. 2014). Anthelmintic resistance has not been described for other mammalian ascarid species. The

54 ability to maintain gastro-intestinal helminths in vitro would enhance the experimental tractability of

55 nematode parasites by facilitating the application of a range of molecular and biochemical tools and

56 analyses in clinically relevant species. Such an advance would prompt a paradigm shift in parasitology

57 research permitting progress in key areas including evaluation of anthelmintics and natural products

58 with anthelmintic properties, (Rapson et al. 1985; Brownlee et al. 1997; O'Grady and Kotze, 2004;

59 Jansen et al. 2013), application of transcriptomics to investigate the genetic mechanisms driving

60 anthelmintic resistance (Jansen et al. 2013), induction of RNAi interference for the identification of

61 novel drug targets (McCoy et al. 2015), analysis of excretory and secretory products (Young et al. 1995;

62 Geldhof et al. 2000, Islam et al. 2004; Cribb et al. 2006; Burk et al. 2014; Thomas et al. 2016), and

63 interrogation of host-parasite interactions (Kotze and McClure, 2001).

Most of the literature on in vitro culture and maintenance of ascarid parasites has focused on

65 the pig nematode, Ascaris suum, where a variety of culture conditions have been employed. Some

66 reports describe in vitro maintenance of larval stages (Douvres and Urban, 1983, 1986), however the

67 size and nutrient requirements of the intestinal stages introduce new challenges to in vitro

68 maintenance. Chehayeb et al. (2014) maintained adult $A$. suum collected from the small intestine of

69 pigs for 24 hours in Locke's solution where glucose was provided as the main nutrient. Weisblat and

70 Russel (1976) described culturing A. suum in artificial perienteric fluid (APF), and Brownlee et al. (1997)

71 maintained worms in APF for five days. Islam et al. (2004) maintained adult A. suum under both aerobic

72 and anaerobic conditions to observe changes in proteome expression patterns. Worms were maintained

73 in Roswell Park Memorial Institute- 1640 (RPMI-1640) medium, and viability was maintained in both 
74 systems for over two weeks. Dmitryjuk et al. (2014) sustained adult $A$. suum in Ascaris ringer's solution

75 (ARS) for 20 hours without any nutrient, while McCoy et al. (2015) maintained $A$. suum for eight days in

76 ARS without any nutrient. In contrast, only two studies have reported the in vitro maintenance of

77 Parascaris spp. Burk et al. (2014) reported culturing of larval stages and maintenance of adult stages to

78 investigate the production of excretory-secretory products. In that study, two adult worms were

79 maintained in RPMI-1640 medium at $37^{\circ} \mathrm{C}$ for five days. Jansen et al. (2013) maintained an undisclosed

80 number of adult worms in APF for 30 hours at $37^{\circ} \mathrm{C}$ for in vitro ivermectin exposure. No attempts have

81 been made to evaluate the requirements for long term in vitro maintenance of Parascaris spp. intestinal

82 stages, nor to characterize their preferred environment and nutrient requirements.

In order to determine the optimum in vitro requirements and monitor the effects of in vitro drug

exposure, it is necessary to ascertain helminth longevity and viability. In vitro evaluation of anthelmintic

85 efficacy in adult worms has been done by determining worm longevity by classifying them on an alive or dead basis (Eguale et al. 2007a, b; Hu et al. 2013). While Hu et al. (2013) implemented a scoring system on a 0-3 scale to assess worm movement, it was still largely subjective and the results considered worms only on an alive (score 1-3) or dead (score 0) basis. Similarly, Richards et al. (1995), described a simple method to monitor drug sensitivity of Necator americanus and Ancylostoma caninum based on the observation of worm motility of treated versus control worms. Worms were characterized as either

91 active or inactive after gentle prodding. Neither the method proposed by Hu et al. (2013) nor Richards et

92 al. (1995) allows for the objective evaluation of worm viability over a series of time points. A similar

93 subjective method was reported by Dmitryjuk et al. (2014) to monitor the effects of in vitro anthelmintic 94 exposure to adult $A$. suum. Later, a motility assay was developed by O'Grady and Kotze (2004) that 95 utilized a scoring system to monitor anthelmintic efficacy against Haemonchus contortus. While the 96 scoring system allows one to observe a decline in viability over time, the definition of each score is 97 subjective as scores are assigned based on the investigators definition of significant movement, and a 
set amount of time for each observation was not described. Marcellino et al. (2012) developed the

99 WormAssay, a high throughput screening method to assess the anthelmintic efficacy against macroparasites based on motility. The WormAssay uses an open source computer software program

101 and a camera to automatically assess worm movement and provide a quantitative measurement.

102 Worms must be placed in microtiter plates, and the system is compatible with plates of either $6,12,24$,

10348 , or 96 wells. The Parascaris species, however, are still too large for the well plates used in this

104 system. Even the largest wells (6-well plate) measuring approximately $3.48 \mathrm{~cm}$ in diameter are not large 105 enough for a mature Parascaris spp., which are commonly over $10 \mathrm{~cm}$ long (Clayton and Duncan, 1978).

106 The Worminator uses a similar method but is specifically designed for determining the motility of

107 microscopic nematode stages (Storey et al. 2014).

108 The purpose of this study was to characterize appropriate in vitro conditions for maintaining 109 intestinal Parascaris spp., and to establish a scoring system to monitor worm viability over several time 110 points.

\section{Materials and Methods}

$113 \quad 2.1$ Parasite sources

The study took place over the course of eight foal necropsies from October 2016 to October

115 2017. The foals were born in a herd housed at the University of Kentucky that has not been treated with 116 any anthelmintics since 1979 and has been documented to harbor a variety of equine parasites through 117 natural infection (Lyons et al. 1990). The foals employed in the study consisted of five colts and three 118 fillies. Foals were humanely euthanized when they reached 4.5-5 months old and subsequently 119 necropsied. The research was conducted following approval from the University of Kentucky's 120 Institutional Animal Care and Use Committee (IACUC) under protocol number 2012-1046. 
122

\subsection{Study Design}

During the first phase of this study (necropsies 1-3) worms were monitored on an alive/dead basis in order to make initial observations on the necessary conditions for in vitro maintenance and nutrient requirements of Parascaris spp. specimens. The second phase (necropsies 4-8) commenced following the development of a scoring system to objectively assess the viability of Parascaris spp. specimens under various environmental and nutrient conditions.

A variety of different media types nutrient supplements and environmental conditions were examined (see Section 2.4.1 and 2.4.2). The number of worms evaluated for each media, nutrient and environmental condition ( $\mathrm{CO}_{2}$ and platform rocker) is described in Table 1.

\subsection{Collection of Parascaris spp.}

Following necropsy, the small intestine was detached from the stomach and cecum. The intestinal contents were milked out onto a $425 \mu$ mesh sieve. Room temperature (RT) tap water was slowly added to the sieve to dilute the contents to better visualize the worms. Intestinal stages of Parascaris spp. (adult and fourth larval stage, $\mathrm{L}_{4}$ ) specimens were recovered using a spay hook and placed in a container of RT media of either ARS (see Table 2 for composition) (necropsies 1-6) or RPMI1640 (R8758, Sigma-Aldrich, St. Louis, MO, US) (necropsies 7 and 8). The container was placed into a water bath maintained at $37^{\circ} \mathrm{C}$ for transport to the laboratory. Worms were classified as adult or $L_{4}$, and adult worms were further characterized by sex. Worms were considered adults when gonads were visible as white material in the mid-section of the worm. Males were differentiated from females by being smaller and having less gonad material than females, and occasionally presented with a curved hook in the tail. Immature worms $\left(\mathrm{L}_{4}\right)$ did not have any visible gonad material. 
2.4 In vitro maintenance of Parascaris spp.

Worms were maintained in vented TPP tissue culture flasks (300 cm², MidSci, St. Louis, MO) containing $200 \mathrm{~mL}$ of the pre-assigned medium. Media were changed every 12 hours. This was done by placing a cell strainer of $400 \mu \mathrm{m}$ pore size (pluriSelect Life Science, Leipzig, Germany) over the mouth of

149 the flask and allowing the old media to flow through while keeping the worms in the flask to limit 150 handling and subsequent damage. New media, pre-warmed to $37^{\circ} \mathrm{C}$, were then added to the flask. The 151 flasks were kept in the pre-determined incubator with or without $\mathrm{CO}_{2}(5 \%)$ supplementation at $37^{\circ} \mathrm{C}$. In the first phase of the study (necropsies 1-3) worms were maintained in groups of four or five,

153 containing two males and at least one female and one $L_{4}$ worm. In the second phase of the study

154 (necropsies 4-8) a total of five worms were placed in each culture flask consisting of either two males, 155 one female, and two immatures, or three males, one female, and one $L_{4}$ worm. The variation in worm 156 stage/sex within each cohort was due to the number of worms per category collected at each necropsy.

\subsubsection{Preparation of culture media}

Media (ARS, APF, ARS 3x Tris, APF 2x NaCl, physiological saline (PS) (Hospira Inc, Lake Forest, IL,

160 US), homemade physiological saline (HMPS), and RPMI-1640; see Table 2) were freshly prepared, stored 161 at $4^{\circ} \mathrm{C}$, and then warmed to $37^{\circ} \mathrm{C}$ prior to adding to the culture flasks. Streptomycin (1mg / $\left.1 \mathrm{~L}\right)$, Penicillin $162(1000 \mathrm{U} / 1 \mathrm{~L})$ and Amphotericin-B $(10 \mu \mathrm{g} / 1 \mathrm{~L})$ were added to all media types, except when Escherichia coli 163 was added as a nutrient (see 2.4.2). All media types were employed within 24 hours of preparation. 
A list of the nutrients and their respective concentrations can be found in Table 2. Escherichia coli

167 OP50 (University of Kentucky) was prepared in the following manner. LB (lysogeny broth) (Miller 168 formulation, ThermoFisher Scientific, Waltham, MA) and LB-agar (Fisher Scientific, Hampton, NH) were 169 prepared according to the manufacturer's instructions. Escherichia coli OP50 (University of Kentucky) 170 were cultured in $15 \mathrm{~mL}$ of $\mathrm{LB}$ broth overnight at $37^{\circ} \mathrm{C}$ in a shaking incubator at $225 \mathrm{rpm}$. Following 171 incubation, cells were pelleted by centrifugation at $3220 \mathrm{~g}$ for eight minutes. After centrifugation, the 172 supernatant was decanted and pelleted. E. coli were re-suspended in $15 \mathrm{~mL}$ of filter-sterilized culture 173 media. Colony forming units (CFUs) were determined for the E. coli suspension by plating ten-fold serial 174 dilutions to determine the starting culture concentration (i.e. input). The remaining suspension was 175 equally divided and added to the assigned flasks. One flask was kept without worms as a control. Prior to 176 the media changes, an aliquot of the media from the culture flasks, including the flask without worms, 177 was plated to determine the final concentration (i.e. output) of surviving E. coli.

\subsubsection{Environmental conditions}

The environmental conditions assessed were the use of a $5 \% \mathrm{CO}_{2}$ incubator and platform rocker.

181 The number of flasks assigned to each condition can be found in Table 1. Pre-assigned flasks were placed 182 in a $5 \% \mathrm{CO}_{2}$ incubator at $37^{\circ} \mathrm{C}$ for the entirety of their survival. Flasks assigned to the platform rocker 183 (Hofer Scientific Instruments, San Francisco, CA model PR70) were maintained at approximately $60 \mathrm{rpm}$ 184 within the air-only incubator at $37^{\circ} \mathrm{C}$ for the entirety of their survival. 
For the first phase of the study (necropsies 1-3), worms were monitored on an alive or dead 188 basis and the number of worms surviving per flask at each time point/media change was recorded (i.e. longevity). Worms were considered dead when they became flaccid and/or displayed signs of decay. Flaccidity was determined by placing the worm over a pair of forceps at midpoint and carefully lifting it 191 out of the medium. If the worm draped loosely over the forceps and appeared as an acute angle, it was 192 considered flaccid. Decay was noted visually and determined as breakdown of the exterior cuticle. The 193 second phase of the study (necropsies 4-8) began with the development of an objective scoring system 194 to monitor worm viability. Prior to each medium change, worm viability was assessed and awarded a 195 score according to the descriptions in Table 3. Each worm was observed for 15 seconds for movement 196 while remaining in the flask. If no movement occurred during the 15 second observatory period, forceps 197 were used to gently stimulate the worm in an attempt to initiate movement. If still no movement was 198 observed, the forceps were used to assess flaccidity and check for decay as previously described. Dead 199 worms were removed from the flask and discarded.

\subsection{Statistical Analyses}

For the first phase of the study (necropsies 1-3), a percent reduction in the number of worms in each flask was calculated at each time point. The final time of longevity was considered when all worms in a flask had died. Mean longevity with $95 \%$ confidence intervals $(\mathrm{Cl})$, and the range for media, nutrient, and incubator type were calculated using Microsoft Excel 2016 (Redmond, WA, USA). These values can

207 be found in Table 4. 
constructed to determine which media, nutrient supplementation profile, and incubator type

211 significantly affected worm longevity. 'Percent loss' was the response variable for all analyses. The first

212 model assessed the longevity of worms maintained in the different media types without nutrient

213 supplementation or $\mathrm{CO}_{2}$ incubator. The covariates were 'Time' and the interaction term 'media

214 ID*none', where 'none' implied an air incubator and no nutrients were used. 'Necropsy date' was kept

215 as a random effect. The second analysis was used to analyze the supplementation with glucose in all

216 types of media because it was the only nutrient tested across all media types. The interaction term

217 'Media ID*glucose' was the covariate analyzed and 'necropsy date' was kept as the random effect. The

218 third model examined worm longevity when maintained in ARS media supplemented with either

219 glucose, gelatin, E. coli, yeast, FBS, cholesterol, or gelatin and glucose. ARS was the only medium

220 supplemented with all the nutrients and therefore was the only medium examined in this model.

221 'Nutrient' and 'time' were the covariates examined. 'Necropsy date' and ' $\mathrm{CO}_{2}$ ' were kept as random

222 effects. The fourth model examined the use of the $\mathrm{CO}_{2}$ incubator across all media and nutrient

223 supplements. The covariates examined were 'time' and ' $\mathrm{CO}_{2}{ }^{\prime}$. 'Necropsy date', 'Media ID' and 'nutrient'

224 were kept as random effects. The fifth analysis analyzed the stage ( $\mathrm{L}_{4}$ or adult) and sex (adult worms

225 only) over time, regardless of media, nutrients used, or the use of the $\mathrm{CO}_{2}$ incubator. The covariates

226 analyzed were 'stage' and 'sex'. 'Media ID' and 'necropsy date' were kept as random effects. Any time a

227 significant covariate ( $\alpha=0.05)$ was observed, a 'least squares means' analysis was performed for a

228 Tukey's pair-wise comparison.

For the second phase of the study (necropsies 4-8), the scoring system (see Table 3) was used to 232 monitor worm viability. Mean worm viability per flask at each time point was calculated. Worms that 
233 had died continued to receive a score of zero and were included in the mean calculation until all the 234 worms within the same flask had died. Mean values and $95 \%$ confidence intervals $(\mathrm{Cl})$ were calculated using Microsoft Excel 2016 (Redmond, WA, USA). The percent viability per flask was calculated in Microsoft Excel for each time point using the following formula, where ' $X$ ' refers to each time point:

$$
\% \text { Viability }=100-\left(\frac{\left(\text { initial score }- \text { score at time }{ }^{\prime} X^{\prime}\right)}{\text { initial score }} \times 100 \%\right)
$$

Further statistical analyses were performed using SAS software (version 9.4, SAS Institute, Cary, North Carolina, USA). Here, a total of six mixed linear models with repeated measures across time were performed to determine which media, nutrients, and environmental conditions significantly affected worm viability. For all models, 'percent viability' was the response variable. The first model assessed the viability of worms maintained in the different media without nutrient supplementation, $\mathrm{CO}_{2}$ incubator, 243 or platform rocker. The covariates were 'time' and the interaction term 'media ID*none', where 'none' 244 implied that no nutrients or environmental conditions were implemented. 'Necropsy date' was kept as a random effect. The second model analyzed worm viability when maintained in one of the saline-based media (i.e. ARS, APF, ARS 3x Tris, APF 2x NaCl, PS, HM PS) with glucose compared to worm viability 247 maintained in the same saline-based media without glucose. Glucose was the only nutrient added across 248 all saline-based media types and therefore was the only nutrient analyzed in this model. The covariates examined were 'time' and the interaction term 'media ID*glucose'. 'Necropsy date' was kept as a 250 random effect. The third model examined worm viability when maintained in APF media supplemented 251 with either glucose, FBS, cholesterol, a combination of FBS and cholesterol, Tween only control, or as a 252 no nutrient control. APF was the only medium supplemented with all the nutrients and therefore was 253 the only medium examined in this model. 'Nutrient' and 'time' were the covariates examined. 'Necropsy 254 date' and 'environment' (i.e. $\mathrm{CO}_{2}$ incubator or platform rocker) were kept as random effects. The fourth 255 model examined the use of the platform rocker and $\mathrm{CO}_{2}$ incubator across all media and nutrient 
256 supplements. The covariates examined were 'time' and 'environment'. 'Necropsy date', 'Media ID' and

257 'nutrient' were kept as random effects. The fifth model analyzed the use of RPMI against all media,

258 nutrients, and environmental conditions. The covariate tested was 'RPMI,' and 'necropsy date' was kept

259 as random effect. The last model analyzed the stage ( $L_{4}$ or adult) and sex (adult worms only) over time,

260 regardless of media, nutrients used, or the use of the $\mathrm{CO}_{2}$ incubator or platform rocker. The covariates

261 analyzed were 'stage' and 'sex'. 'Media ID', and 'necropsy date' were kept as random effects. Any time a

262 significant covariate $(\alpha=0.05)$ was observed, a 'least squares means' analysis was performed for a

263 Tukey's pair-wise comparison.

264

265 3. Results

A total of 212 cultures were performed and a total of 1045 Parascaris spp. worms were used.

267 The number of cultures and worms per media type, nutrient supplementation, and environmental

268 condition (incubator type and/or platform rocker) can be found in Table 2.

\subsection{Phase one: Longevity}

For the first phase of the study pertaining to worm longevity (necropsies 1-3), a total of 210

272 worms were used consisting of 98 adult males, 54 adult females, and $58 \mathrm{~L}{ }_{4} \mathrm{~S}$. During this phase of the

273 study, the worms lived a maximum of 84 hours. The media type employed when considered without

274 nutrient supplementation or $\mathrm{CO}_{2}$ did have a significant effect on worm longevity $(p=0.0100)$, however

275 the least squares means pairwise comparison did not identify any significant differences between

276 media. ARS was the only media type significantly affecting worm viability with the addition of glucose.

277 Worms maintained in ARS supplemented with glucose lived significantly longer than worms maintained 
278 in ARS alone $(p<0.0001)$. There were no significant differences observed in any of the other media types

279 supplemented with glucose compared to when glucose was not added. Regarding the various types of

280 nutrient supplementation with the ARS media, worms maintained with glucose $(p<0.0006)$ or a

281 combination of glucose and gelatin $(p<0.0001)$ had significantly better longevity than worms maintained

282 without any nutrient. Worms maintained with glucose had significantly better longevity than worms

283 maintained with E. coli $(p=0.0008)$, yeast $(p<0.0001)$, FBS $(p=0.0013)$, or cholesterol $(p=0.0279)$.

284 Similarly, worms maintained with a combination of glucose and gelatin had significantly better longevity

285 than those maintained with gelatin only $(p=0.0484)$, E. coli $(p<0.0001)$, yeast $(p<0.0001), F B S(p<0.0001)$,

286 or cholesterol $(p=0.0008)$. The mean longevity, $95 \%$ confidence intervals, and range of longevity for the

287 different nutrients and incubator type can be found in Table 4. The use of a $\mathrm{CO}_{2}$ incubator did not

288 significantly affect worm longevity $(p=0.2854)$. 'Adult male $(p=0.0021)$ and female $(p<0.0001)$ worms

289 had significantly better longevity than immature worms, however there was no significant difference

290 between males and females $(p=0.5780)$. The mean longevity, 95\% confidence intervals, and range of

291 longevity for immatures, males, and females can be found in Table 4.

\subsection{Phase two: Viability}

For the second phase of the study pertaining to worm viability (necropsies 4-8), a total of 835

295 worms were used, consisting of 350 adult males, 215 adult females, and 270 L4s. The RPMI-1640 media

296 resulted in significantly better worm viability than any of the other media $(p<0.0001)$ (Figure 1$)$. APF $2 x$

$297 \mathrm{NaCl}$ had significantly better viability than ARS $(p=0.0002)$. APF $(p=0.0005)$, ARS $3 x$ Tris $(p=0.0169)$, and

298 APF $2 x \mathrm{NaCl}(p<0.0001)$ had significantly better viability than the homemade physiological saline. The

299 addition of glucose to the saline-based media did not significantly affect worm viability compared to 300 those maintained in the saline-based media without glucose $(p=0.3048)$. The addition of a nutrient to 
301 the APF medium did significantly decrease worm viability $(p=0.0413)$, however the least squares means

302 pairwise comparison did not identify any significant differences (Figure 2). The use of the platform

303 rocker resulted in significantly better worm viability than worms maintained without the rocker

$304(p=0.0305)$, while there were no significant differences in worm viability between the use of an air or

$305 \mathrm{CO}_{2}$ incubator ( $p=1.0000$ ) (Figure 3). Overall, worms maintained in RPMI-1640 had significantly better

306 viability than worms maintained with any other method regardless of media, nutrient, or environmental

307 condition $(\mathrm{p}<0.0001)$ (Figures 1 and 2 ). In regards to worm stage and sex, adult worms regardless of sex

308 had significantly better viability than $L_{4} S(p<0.0001)$ and females had significantly better viability than

309 males $(p<0.0001)$ across all media types, nutrient supplementation, and environmental conditions.

\section{$311 \quad 4.0$ Discussion}

This is the first study to determine the preferred in vitro conditions for the intestinal stages of

313 Parascaris spp., and to describe a reliable and objective method for assessing their viability. Worm

314 motility and the presence of muscle tone appears to be reliable indicator for assessing in vitro

315 conditions. This study is the first to report a difference in in vitro worm viability for Parascaris spp.

316 between $L_{4}$ and adult stages, as well as between male and female adult worms.

Intestinal stages of Parascaris spp. must be active swimmers against the flow of intestinal

318 contents in order to maintain their position in the host and avoid being expelled by peristalsis (Drudge

319 and Lyons, 1983). Therefore, worm responses to in vitro conditions should be judged based on activity

320 level, where a decrease in activity likely reflects a decrease in overall worm viability. Other scoring

321 systems for gastrointestinal nematodes have been developed, but these did not provide strict

322 parameters of movement per score (Richards et al. 1995; O'Grady and Kotze, 2004). While Parascaris

323 spp. intestinal stages are not compatible with the current size restrictions of the WormAssay (Marcellino 
324 et al. 2012), a modification of this technique to accommodate larger macroparasites should be a target

325 for future research.

The use of RPMI-1640 media resulted in significantly better worm viability than all other media

327 types regardless of nutrient supplementation and/or environmental condition (Figures 1 and 2). Worms

328 lived a maximum of 168 hours in RPMI-1640 (Figures 1 and 2), which is well above the 84 and 96 hours

329 achieved in phase 1 and phase 2, respectively, with the addition of glucose (Table 3 and Figure 2). At this

330 time, it is unknown which components of the RPMI-1640 media caused this improvement in viability and

331 longevity, but it is likely due to the combination of vitamins and amino acids that were missing from the

332 other media evaluated. This finding is in agreement with Urban et al. (1984) who found improved

333 growth and survival of $\mathrm{L}_{4} A$. suum when cultured in RPMI-1640 rather than a saline medium

334 supplemented with glucose.

The use of sugar (glucose or dextrose) as a nutrient is reported in several other studies

maintaining adult stages of $A$. suum (Weisblat and Russel, 1976; Brownlee et al. 1997; Chehayeb et al.

337 2014), and one study used dextrose for maintaining adult $P$. equorum (Jansen et al. 2013). While it is

assumed that sugar is necessary for the in vitro cultivation of Ascaris and Parascaris species, this had not

339 previously been evaluated in a published study. In phases one and two of this study, Parascaris spp.

340 survived a maximum of 84 and 96 hours, respectively, when glucose was added as a nutrient and it did

341 not significantly affect worm viability. The success of the RPMI-1640, but not the glucose provides

342 evidence that Parascaris spp. intestinal stages require different and/or additional nutrients beyond

343 glucose for sustainment in vitro. It is interesting that $A$. suum can be maintained for eight days in ARS

344 without any nutrient supplementation (McCoy et al. 2015). In the current study, Parascaris spp. did not

345 live more than 168 hours in any of the media regardless of the media type or nutrient provided. This

346 may suggest that adult $A$. suum and Parascaris spp. worms have very different nutrient and metabolic 
requirements, however direct conclusions cannot be made at this time. A comparative study could be performed to determine the viability of Parascaris spp. and $A$. suum when supplemented with different nutrients, and analyses of the media after a nutrient has been provided could determine if the worms successfully ingested the nutrient. If so, the effectiveness of the worm to generate energy from the given nutrient could be assessed using metabolic techniques. Such findings would provide significant advances toward in vitro techniques of the parasitic stages.

Douvres and Urban $(1983,1986)$ described methods for culturing larval stages of Ascaris species utilizing various gaseous stages, including $5 \% \mathrm{CO}_{2}$. Several studies report the maintenance of adult $A$. suum worms without $\mathrm{CO}_{2}$ (Weisblat and Russel, 1976; Brownlee et al. 1997; Chehayeb et al. 2014; McCoy et al. 2015). Jansen et al. (2013) maintained $P$. equorum adult worms without $5 \% \mathrm{CO}_{2}$ while Burk et al. (2014) cultured second and third larval stages of $P$. equorum under $5 \% \mathrm{CO}_{2}$ conditions, but not the adult worms. Based on these reports, it appears that adult worms may not require $\mathrm{CO}_{2}$, but this had not been specifically evaluated for Parascaris spp. The current study did not find the use of $5 \% \mathrm{CO}_{2}$ to significantly affect worm longevity or viability (Figure 3). However, this study did not investigate the impact of $\mathrm{CO}_{2}$ on worms maintained in RPMI-1640 and this should be evaluated in future studies.

The use of a platform rocker for in vitro maintenance of ascarid parasites had not been evaluated prior to this study. In this study, the use of the rocker significantly improved worm viability (Figure 3), however no firm conclusions can be made at this time. The platform rocker could not be tested simultaneously with $\mathrm{CO}_{2}$ due to limited space in the incubator. Furthermore, this study did not evaluate RPMI-140 media with the use of the rocker, and this should be investigated in future studies.

It is also known that nematodes are unable to synthesize cholesterol de novo (Dutky et al. 1967; Cole and Krusberg, 1968), however this study did not find the addition of cholesterol to improve worm longevity or viability. Additionally, the addition of FBS did not significantly improve viability. These 
findings are interesting because Urban et al. (1984) found the addition of cholesterol $(50 \mu \mathrm{g} / \mathrm{mL})$ and

371 serum (10\%) to RPMI-1640 to have an additive effect on the growth of $\mathrm{L}_{4} A$. suum. Urban et al. (1984)

372 also found that an increase in cholesterol concentration to $250 \mu \mathrm{g} / \mathrm{mL}$ from $50 \mu \mathrm{g} / \mathrm{mL}$ reversed this

373 effect. While the aforementioned study examined the development of larval stages, it is possible that a

374 similar scenario was observed in the current study where the Parascaris spp. intestinal stages were

375 negatively impacted by the cholesterol concentration examined herein. Future studies should

376 investigate varying concentrations of cholesterol to determine if there is an optimum concentration

377 and/or a tolerance threshold.

The varying sample sizes between the nutrient trials are a limitation to this study, particularly in regards to the number of worms used for evaluating the RPMI-1640 media and the saline-based medias supplemented with cholesterol, FBS, yeast, and E. coli (Table 1). Variations occurred due to the number

381 of worms harvested at each necropsy. While the results of this study clearly support he

382 recommendation for using RPMI-1640 for maintaining intestinal stages of Parascaris spp., the conclusions should be interpreted with caution and warrant further investigation. The effects of stocking

384 density and keeping male, female, and immature worms together would also provide interesting points 385 for future studies.

It is important to note that the in vivo immune responses exhibited by the foal prior to necropsy

387 may also affect worm viability in vitro. Foals typically gain immunity to Parascaris spp. worms around

388 nine months of age (Clayton and Duncan, 1979). Some response by the immune system to the present 389 parasites is expected and it is unknown how the parasites were affected prior to harvest and culturing. 390 This variability was controlled for by using foals which were all born into the same herd, and harvesting 391 the worms when the foals were between 4.5-5 months of age which is the peak age for Parascaris spp. 392 burden (Fabiani et al. 2016) and thus minimizing the potential influence of host immunity. 
In summary, the scoring system proved to be a useful method for monitoring $\mathrm{L}_{4}$ and adult worm

394 viability in vitro, and should be considered for future studies. This study found RPMI-1640 media to 395 significantly improve worm viability. The use of a $5 \% \mathrm{CO}_{2}$ incubator did not significantly affect worm 396 viability, but a platform rocker significantly increased viability. The viability of adult worms was also 397 significantly better than that of $L_{4} S$. Further investigations should be performed to examine the effects 398 of a platform rocker and $\mathrm{CO}_{2}$ incubator when RPMI-1640 is used as the culture media.

\section{Conflict of Interest Statement}

401 The authors declare no conflict of interest.

\section{Acknowledgements}

405 We are very gracious to the farm staff for caring so well for the equine research herd. We also extend 406 our gratitude to members of the Nielsen laboratory for assisting with the necropsies, and especially to 407 the late Dr. Eugene Lyons and Sharon Tolliver for sharing their abundance of knowledge and expertise in 408 leading the necropsy team.

\section{Financial Support}

411 This research was supported by the Gluck Equine Research Foundation. 
414 Bolla, RI, Weinstein, PP, Lou, C (1972) In vitro nutritional requirements of Nippostrongylus brasiliensis- I. Effects of sterols, sterol derivatives, and heme compounds on the free-living stages. Comparative Biochemistry and Physiology. 43B, 487-501.

Brownlee, DJA, Holden-Dye, L, Walker, RJ (1997) Actions of the anthelmintic ivermectin on the pharyngeal muscle of the parasitic nematode, Ascaris suum. Parasitology. 115, 553-561.

Burk, SV, Dangoudoubiyam, S, Brewster-Barnes, T, Bryant, UK, Howe, DK, Carter, CN, Vanzant, ES,

Chehayeb, JF, Robertson, AP, Martin, RJ, Geary, TG (2014) Proteomic analysis of adult Ascaris suum fluid compartments and secretory products. PLoS Neglected Tropical Diseases. 8:6, e2939. DOI: 10.1371/journal.pntd.0002939.

Clayton, HM and Duncan, JL (1978) Clinical signs associated with Parascaris equorum infection in wormfree pony foals and yearlings. Veterinary Parasitology. 4, 69-78. DOI:10.1016/03044017(78)90037-7.

Clayton, HM and Duncan, JL (1979) The development of immunity to Parascaris equorum infection in the foal. Research in Veterinary Science. 26, 383-384. DOI:10.1016/0024-3205(68)90315-9. 
Cribb, NC, Corté, NM, Bouré, LP, Peregrine, AS (2006) Acute small intestinal obstruction associated with Parascaris equorum infection in young horses: 25 cases (1985-2004). New Zealand Veterinary Journal. 54, 338-343. DOI: 10.1080/00480169.2006.36721.

Dmitryjuk, M, Łopieńska-Biernat, E, Zaobidna, EA (2014) The In vitro effect of ivermectin on the activity of trehalose synthesis pathway enzymes and their mRNA expression in the muscle of adult female Ascaris suum (Nematoda). The Scientific World Journal. 2014, 936560. DOI: $10.1155 / 2014 / 936560$

Douvres, FW and Urban, JF Jr. (1983) Factors contributing to the in vitro development of Ascaris suum from second-stage larvae to mature adults. Journal of Parasitology. 69, 549-558. DOI: $10.2307 / 3281369$.

Douvres, FW and Urban, JF Jr. (1986) Development of Ascaris suum from In Vivo-derived Third-stage Larvae to Egg-laying Adults In Vitro. Proceedings of the Helminthological Society of Washington. 53, 256-262.

Drudge, JH and Lyons, ET (1983) Ascariasis. In Robinson, N.E. (eds). Current Therapy in Equine Medicine. W.B. Saunders, Philadelphia, pp. 262-264.

Dutky, SR, Robbins, WE, Thompson, JV (1967) The demonstration of sterols as requirements for the growth, development, and reproduction of the DO-136 nematode. Nematologica. 13:140.

Eguale, T, Tilahun, G, Debella, A, Feleke, A, Makonnen, E (2007a) In vitro and in vivo anthelmintic activity of crude extracts of Coriandrum sativum against Haemonchus contortus. Journal of Ethnopharmacology. 110, 428-433. DOI:10.1016/j.jep.2006.10.003. 
Eguale, T, Tilahun, G, Debella, A, Feleke, A, Makonnen, E (2007b) Haemonchus contortus: In vitro and in vivo anthelmintic activity of aqueous and hydro-alcoholic extracts of Hedra helix. Experimental Parasitology. 116, 340-345. DOI: 10.1016/j.exppara.2007.01.019.

Fabiani, JV, Lyons, ET, Nielsen, MK (2016) Dynamics of Parascaris and Strongylus spp. parasites in untreated juvenile horses. Veterinary Parasitology. 230, 62-66.

Geldhof, P, Claerebout, E, Knox, DP, Jagneessens, J, Vercruysse, J (2000) Proteinases released in vitro by the parasitic stages of the bovine abomasal nematode Ostertagia ostertagi. Parasitology. 121, 639-647. DOI: 10.1017/S0031182000006806.

Hu, Y, Ellis, BL, Yiu, YY, Miller, MM, Urban, JF, Shi, LZ, Aroian, RV (2013) An extensive comparison of the effect of anthelmintic classes on diverse nematodes. PLoS One 8:7, e70702. DOI: doi: 10.1371/journal.pone.0070702.

Islam, MK, Miyoshi, T, Yokomizo, Y, Tsugi, N (2004) The proteome expression patterns in adult Ascaris suum under exposure to aerobic/anaerobic environments analyzed by two-dimensional electrophoresis. Parasitology Research. 93, 96-101. DOI: 10.1007/s00436-004-1101-0.

Jansen, JI, Krücken, J, Demeler, J, Basiaga, M, Kornaś, S, von Samson-Himmelstjerna, G (2013) Genetic variants and increased expression of Parascaris equorum P-glycoprotein-11 in populations with decreased ivermectin susceptibility. PLoS One 8:4, e61635. DOI: doi: 10.1371/journal.pone.0061635.

Kotze, AC and McClure, SJ (2001) Haemonchus contortus utilizes catalase in defence against exogenous hydrogen peroxide in vitro. International Journal for Parasitology. 31, 1563-1571. DOI: 10.1016/S0020-7519(01)00303-4. 
474 Lyons, ET, Drudge, JH, Tolliver, SC (1990) Prevalence of some internal parasites found (1971-1989) in 475 horses born on a farm in Central Kentucky. Journal of Equine Veterinary Science. 10, 99-107. DOI: 10.1016/S0737-0806(06)80114-0.

477

478

479

480

481

482

483

484

485

486

487

488

489

490

491

492

493

494

495

McCoy, CJ, Warnock, ND, Atkinson, LE, Atcheson, E, Martin, RJ, Robertson, AP, Maule, AG, Marks, NJ, Mousley, A (2015) RNA interference in adult Ascaris suum - an opportunity for the development of a functional genomics platform that supports organism-, tissue-, and cell-based biology in a nematode parasite. International Journal for Parasitology. 45, 673-678. DOI:

10.1016/j.ijpara.2015.05.003.

Marcellino, C, Gut, J, Lim, KC, Singh, R, McKerrow, J, Sakanari, J (2012) WormAssay: A novel computer application for whole-plate motion-based screening of macroscopic parasites. PLoS Neglected Tropical Diseases. 6:1, e1494. DOI: 10.1371/journal.pntd.0001494.

O'Grady, J and Kotze, AC (2004) Haemonchus contortus: in vitro drug screening assays with the adult life stage. Experimental Parasitology. 106, 164-172. DOI: 10.1016/j.exppara.2004.03.007.

Peregrine, AS, Molento, MB, Kaplan, RM, Nielsen, MK (2014) Anthelmintic resistance in important parasites of horses: Does it really matter? Veterinary Parasitology. 201, 1-8. DOI: 10.1016/j.vetpar.2014.01.004.

Rapson, EB, Jenkins, DC, Topley, P (1985) Trichostrongylus colubriformis: in vitro culture of parasitic stages and their use for the evaluation of anthelmintics. Research in Veterinary Science. 39, 9094.

Richards, JC, Behnke, JM, Duce, IR (1995) In vitro studies on the relative sensitivity to ivermectin of Necator americanus and Ancylostoma ceylanicum. International Journal for Parasitology. 25, 1185-1191. DOI: 10.1016/0020-7519(95)00036-2 
Storey, B, Marcellino, C, Miller, M, Maclean, M, Mostafa, E, Howell, S, Sakanari, J, Wolstenholme, A, Kaplan, R (2014) Utilization of computer processed high definition video imaging for measuring motility of microscopic nematode stages on a quantitative scale: "The Worminator". International Journal for Parasitology. 4, 233-243. DOI: 10.1016/j.ijpddr.2014.08.003.

Tatz, AJ, Segev, G, Steinman, A, Berlin, D, Milgram, J, Kelmer, G (2012) Surgical treatment for acute small intestinal obstruction caused by Parascaris equorum infection in 15 horses (2002-2011). Equine Veterinary Journal. 44, 111-114. doi: 10.1111/j.2042-3306.2012.00607.x

Thomas, D, Jeyathilakan, N, Basith, SA, Senthilkumar, TMA (2016) In vitro production of Toxocara canis excretory-secretory (TES) antigen. Journal of Parasitic Diseases. 40, 1038-1043. DOI: 10.1007/s12639-014-0630-4.

Urban, JF Jr, Douvres, FW, Xu, S (1984) Culture requirements of Ascaris suum larvae using a stationary multi-well system: increased survival, development and growth with cholesterol. Veterinary Parasitology. 14, 33-42. DOI: 10.1016/0304-4017(84)90131-6.

Weisblat, DA, Russel, RL (1976) Propagation of electrical activity in the nerve cord and muscle syncytium of the Nematode Ascaris lumbricoides. Journal of Comparative Physiology. 107, 293307. DOI: 10.1007/BF00656739.

Young, CJ, McKeand, JB, Knox, DP (1995) Proteinases released in vitro by the parasitic stages of Teladorsagia circumcincta, an ovine abomasal nematode. Parasitology. 110, 465-471. DOI: $10.1017 /$ S0031182000064805. 
518 Figure 1. A graphical representation of mean viability of Parascaris spp. intestinal stages when maintained in various media types (ARS: Ascaris Ringer's solution; APF: artificial perienteric fluid; ARS 3x Tris; ARS with triple the amount of Tris buffer; APF $2 x \mathrm{NaCl}$ : APF with double the amount of $\mathrm{NaCl}$; PS: physiologic saline; HM PS: homemade physiologic saline, and RPMI: Roswell Park Memorial Institute). Error bars represent $95 \%$ confidence intervals ( $\alpha=0.05)$.

Figure 2. A graphical representation of mean viability of Parascaris spp. intestinal stages when maintained in either artificial perienteric fluid (APF) medium only, APF medium supplemented

Figure 3. A graphical representation of mean viability of Parascaris spp. intestinal stages maintained with environmental conditions of a platform rocker or a $5 \% \mathrm{CO}_{2}$ incubator across all media and nutrient types. 'None' implies stationary culture flasks in an air incubator. Error bars represent 95\% confidence intervals ( $\alpha=0.05)$. 
Table 1. Distribution of intestinal stages of Parascaris spp. specimens among the different media, nutrients, and environmental conditions (i.e. $\mathrm{CO}_{2}$ incubator, platform rocker) for in vitro maintenance. The number of worms is listed followed by the number of cultures in parenthesis. The top table is from phase one of the study (necropsies 1-3) for initial observations regarding worm longevity. The bottom table is from phase two of the study (necropsies 4-8) when worm viability was assessed. Cultures were kept at $37^{\circ} \mathrm{C}$.

\begin{tabular}{|c|c|c|c|c|c|c|c|c|c|c|c|c|}
\hline Medium & None $^{a}$ & $\begin{array}{l}\text { Glucose } \\
(5 \mathrm{mM})\end{array}$ & Gelatin & $\begin{array}{c}\text { Glucose } \\
\& \\
\text { Gelatin* }\end{array}$ & $\begin{array}{l}\text { Cholesterol } \\
(50 \mu \mathrm{g} / \mathrm{mL})\end{array}$ & $\begin{array}{c}\text { FBS } \\
(10 \%)\end{array}$ & $\begin{array}{l}\text { E. coli } \\
\text { OP50 }\end{array}$ & $\begin{array}{c}\text { Yeast } \\
(1 \%)\end{array}$ & $\begin{array}{l}\mathrm{CO}_{2}(5 \%) \\
\text { Incubator }\end{array}$ & $\begin{array}{l}\text { Glucose } \\
\& \mathrm{CO}_{2} *\end{array}$ & $\begin{array}{l}\text { Gelatin } \\
\& \mathrm{CO}_{2}{ }^{*}\end{array}$ & Total* \\
\hline ARS & $30(8)$ & $28(6)$ & $10(2)$ & $8(2)$ & $15(3)$ & $15(3)$ & $10(2)$ & $15(3)$ & $17(4)$ & $4(1)$ & $5(1)$ & $140(31)$ \\
\hline APF & $10(2)$ & $5(1)$ & 0 & 0 & 0 & 0 & 0 & 0 & 0 & 0 & 0 & $15(3)$ \\
\hline ARS $3 x$ Tris & $10(2)$ & $10(2)$ & 0 & 0 & 0 & 0 & 0 & 0 & 0 & 0 & 0 & $20(4)$ \\
\hline APF $2 \times \mathrm{NaCl}$ & $10(2)$ & $10(2)$ & 0 & 0 & 0 & 0 & 0 & 0 & 0 & 0 & 0 & $20(4)$ \\
\hline PS & $10(2)$ & $5(1)$ & 0 & 0 & 0 & 0 & 0 & 0 & 0 & 0 & 0 & $15(3)$ \\
\hline Total & $70(16)$ & $58(12)$ & $10(2)$ & $8(2)$ & $15(3)$ & $15(3)$ & $10(2)$ & $15(3)$ & $17(4)$ & $4(1)$ & $5(1)$ & $210(45)$ \\
\hline Medium & None $^{a}$ & $\begin{array}{l}\text { Glucose } \\
(5 \mathrm{mM})\end{array}$ & $\begin{array}{l}\text { Cholesterol } \\
(50 \mu \mathrm{g} / \mathrm{mL})\end{array}$ & $\begin{array}{c}\text { FBS } \\
(10 \%)\end{array}$ & $\begin{array}{c}\text { Cholesterol } \\
\text { \& FBS* }\end{array}$ & $\begin{array}{c}\text { Tween } \\
(5 \%) \\
\text { control }\end{array}$ & $\begin{array}{c}\text { Platform } \\
\text { rocker }\end{array}$ & $\begin{array}{l}\mathrm{CO}_{2}(5 \%) \\
\text { Incubator }\end{array}$ & $\begin{array}{l}\text { Glucose } \\
\& \mathrm{CO}_{2}{ }^{*}\end{array}$ & $\begin{array}{c}\text { Glucose } \\
\& \\
\text { Rocker* }\end{array}$ & & Total* \\
\hline ARS & $25(5)$ & $35(7)$ & 0 & 0 & 0 & 0 & $15(3)$ & $10(2)$ & $5(1)$ & $5(1)$ & & 85 (17) \\
\hline APF & $65(13)$ & 195 (39) & $60(12)$ & $60(12)$ & $30(6)$ & $20(4)$ & $15(3)$ & $90(18)$ & 85 (17) & $5(1)$ & & 505 (101) \\
\hline ARS $3 x$ Tris & $25(5)$ & $35(7)$ & 0 & 0 & 0 & 0 & $15(3)$ & $10(2)$ & $5(1)$ & $5(1)$ & & 85 (17) \\
\hline APF $2 \times \mathrm{NaCl}$ & $15(3)$ & $35(7)$ & 0 & 0 & 0 & 0 & $15(3)$ & $5(1)$ & $5(1)$ & $5(1)$ & & 70 (14) \\
\hline PS & $10(2)$ & $15(3)$ & 0 & 0 & 0 & 0 & $5(1)$ & 0 & 0 & 0 & & $30(6)$ \\
\hline HM PS & $10(2)$ & $10(2)$ & 0 & 0 & 0 & 0 & $5(1)$ & 0 & 0 & 0 & & $25(5)$ \\
\hline RPMI-1640 & 35 (7) & 0 & 0 & 0 & 0 & 0 & 0 & 0 & 0 & 0 & & $35(7)$ \\
\hline Total* & 185 (37) & $325(65)$ & 60 (12) & 60 (12) & $30(6)$ & $20(4)$ & $70(14)$ & $115(23)$ & $100(20)$ & $20(4)$ & & 835 (167) \\
\hline
\end{tabular}

a 'None' implies an air incubator and no nutrient was used.

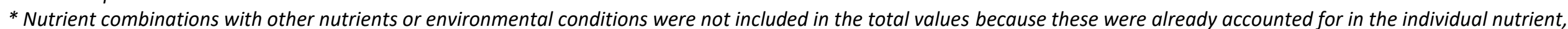
$\mathrm{CO}_{2}$, and platform rocker columns.

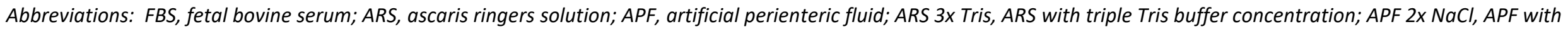

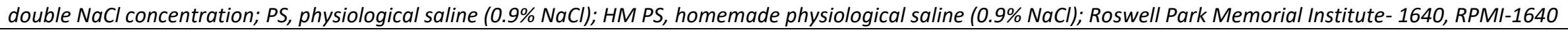




\begin{tabular}{|c|c|}
\hline Score & Description \\
\hline 0 & $\begin{array}{l}\text { Dead, no movement observed independently nor when stimulated with forceps. Lack of muscle tone/flaccid over forceps } \\
\text { when lifted out of the solution. Signs of decay may be present. }\end{array}$ \\
\hline 1 & No movement observed independently nor when stimulated with forceps. Muscle tone is apparent. \\
\hline 2 & Movement only when stimulated with forceps. \\
\hline 3 & Movement of head only without stimulation. \\
\hline 4 & 1-3 whole body movements without stimulation. \\
\hline 5 & 4-6 whole body movements without stimulation. \\
\hline 6 & 7 or more whole body movements without stimulation. \\
\hline
\end{tabular}


Table 4. Mean longevity of intestinal stages of Parascaris spp. in vitro with various nutrients and $\mathrm{CO}_{2}$ incubator use, and of different stages and sex (necropsies 1-3). Worms were maintained in tissue culture flasks $\left(300 \mathrm{~cm}^{2}\right)$ in groups of four or five. All worms were kept in $200 \mathrm{~mL}$ of Ascaris ringer's solution and incubated at $37^{\circ} \mathrm{C}$. The time of longevity was considered the hour when all worms in a flask were dead. Flasks were checked every 12 hours. 95\% confidence intervals are included in parenthesis $(\alpha=0.05)$.

\begin{tabular}{lll}
\hline Nutrient/Incubator & Mean Longevity (hours) & Range of longevity (hours) \\
\hline None $^{a}$ & $42(34.7-49.3)$ & $12-60$ \\
Glucose (5 mM) & $72(63.7-80.3)$ & $48-84$ \\
Gelatin & $72(63.7-80.3)$ & $60-84$ \\
Glucose \& Gelatin & $78(69.7-86.3)$ & $72-84$ \\
Cholesterol $(50 \mu \mathrm{g} / \mathrm{mL})$ & $56(49.6-62.4)$ & $48-60$ \\
Fetal Bovine Serum (10\%) & $40(33.6-46.4)$ & $36-48$ \\
E. Coli OP50 & 36 & 36 \\
Bacto Yeast Extract (1\%) & 36 & 36 \\
$5 \% \mathrm{CO}_{2}$ Incubator & $67.2(54.6-79.8)$ & $48-84$ \\
Glucose \& $\mathrm{CO}_{2}$ Incubator & 84 & 84 \\
Gelatin \& $\mathrm{CO}_{2}$ Incubator & 60 & 60 \\
Total & $46(42.4-49.7)$ & \\
\hline Stage/Sex & Mean Longevity (hours) & Range of longevity (hours) \\
\hline Immature & $38(34.9-41.2)$ & $12-84$ \\
\hline Male & $43(3.3-39.7)$ & $24-84$ \\
\hline Female & $46.5(42.3-50.7)$ & $24-84$ \\
\hline${ }^{\prime}$ None' implies an air incubator and no nutrient was used.
\end{tabular}




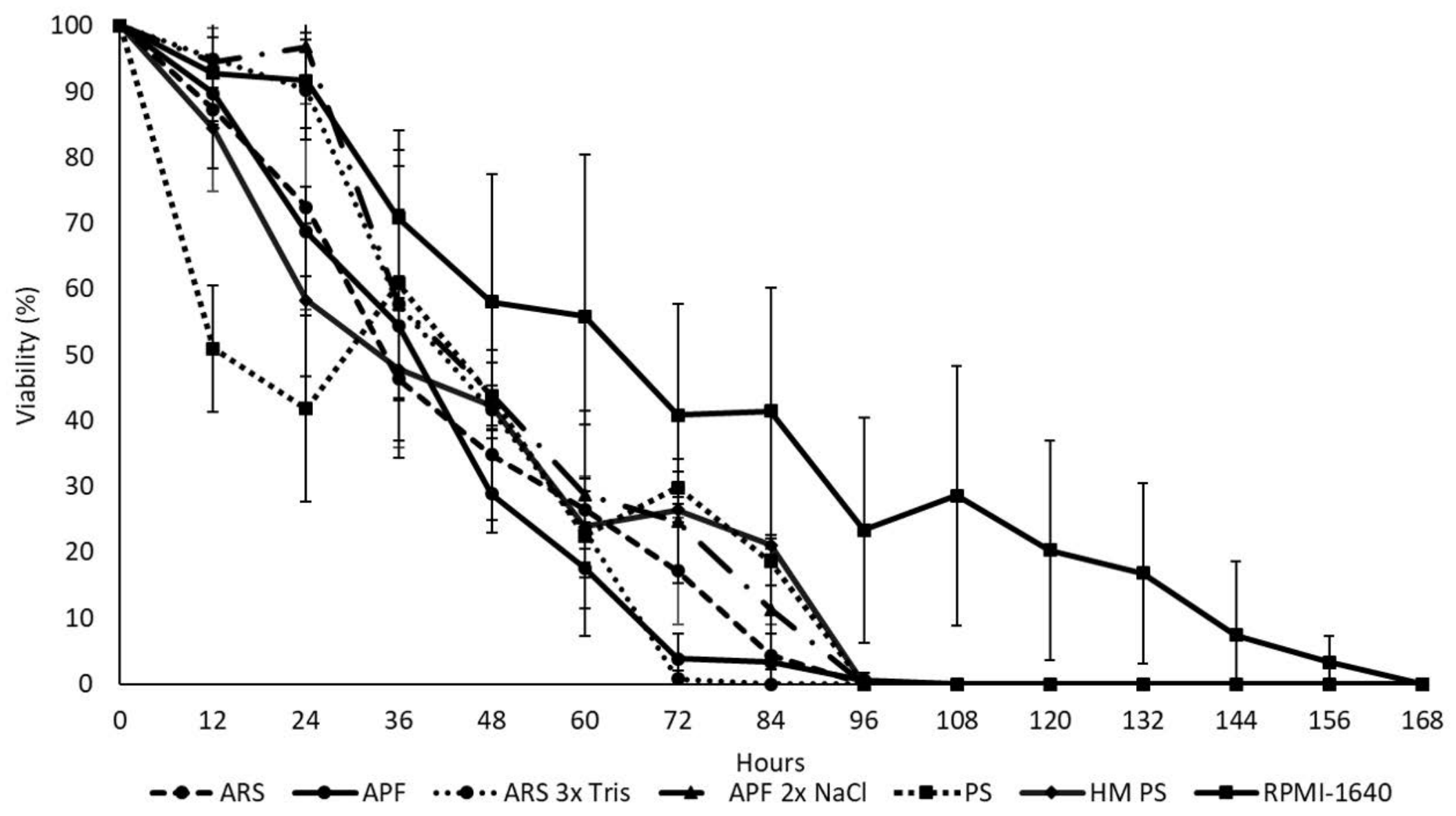




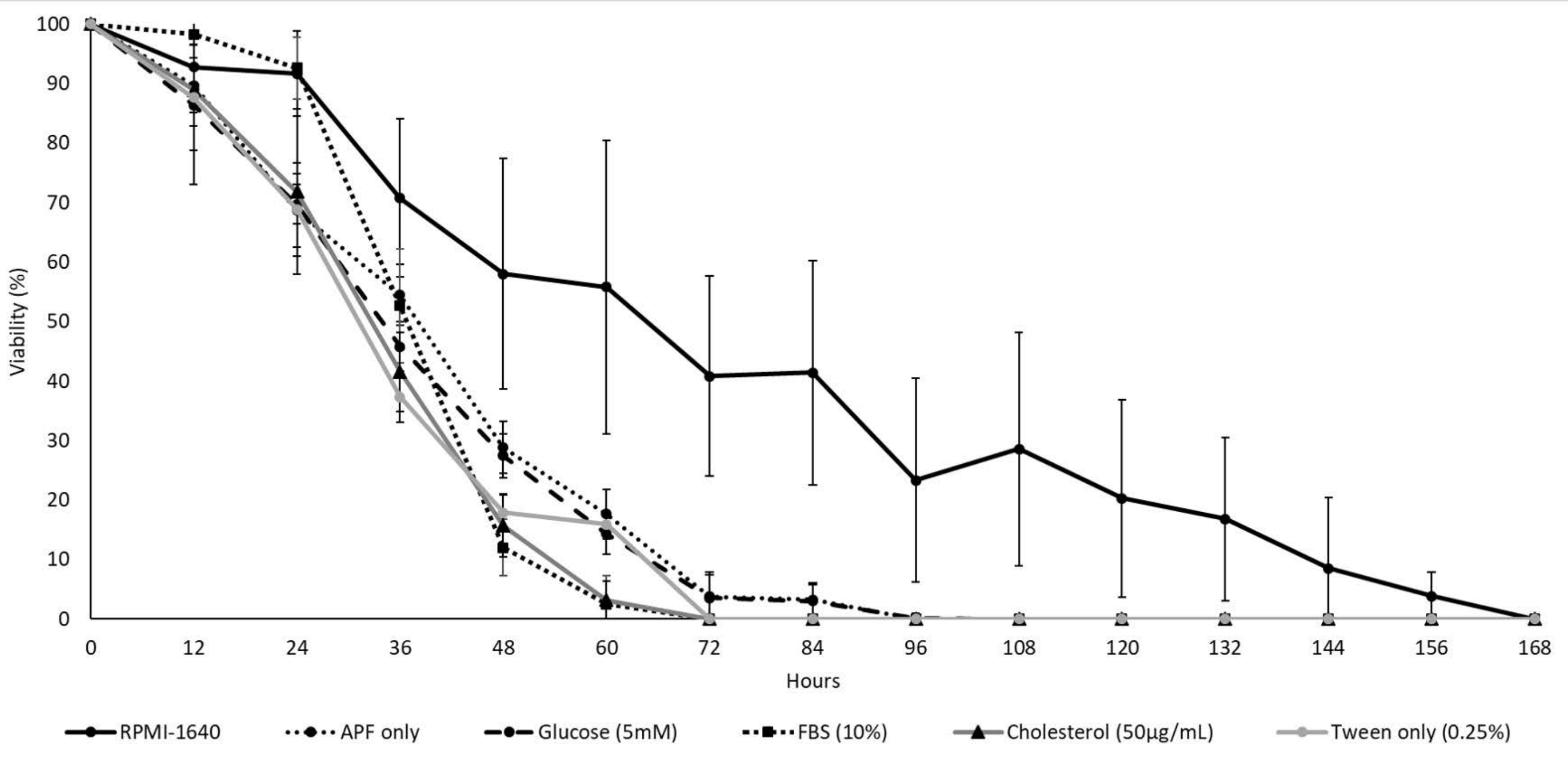


